\title{
Síndrome del primer arco branquial
}

Dr. Jaime Herrera Valle*

Este síndrome corresponde a una falla genética de la irrigación del primer y también del segundo arco branquial, por anomalias en la conformación de la carótida interna y externa que derivan de los tres primeros arcos aórticos. Es un síndrome bastante complejo y comprende numerosos cuadros. Fundamentalmente compromete los elementos que se encuentran en la cara (ojos, nariz y boca), pero puede comprometer también los oídos externo y medio, el cráneo, el cuello, la columna cervical y las manos.

El primer caso descrito es probablemente muy antiguo. Von Arlt describe un síndrome de Goldenhar, en 1845. T. Collins describió su síndrome en 1900, y P. Robin la glosoptosis que lleva su nombre, en 1926. Sin embargo, es sólo en 1955 cuando Mackenzie y Craig hicieron una síntesis de todos estos cuadros basándose en la patogenia similar de estos síndromes. Como ya lo habíamos adelantado, la causa primordial de este síndrome es la falla de irrigación de la porción cefálica del embrión a partir de una malformación de la arteria estapédica que corresponde a la fase intermedia del paso de los primeros arcos aórticos a la formación de las arterias carótidas primitivas, externas e internas. Para comprender mejor este mecanismo, haremos una breve descripción del desarrollo embriológico, oídos externo y medio de la cara y de los arcos branquiales y aórticos.

\section{EMBRIOGÉNESIS DE LA CARA}

En la formación de la cara intervienen tres procesos que derivan de la porción cefálica del ectoderma y son los maxilares, nasales y frontal (Fig. 1).

Fig. 1

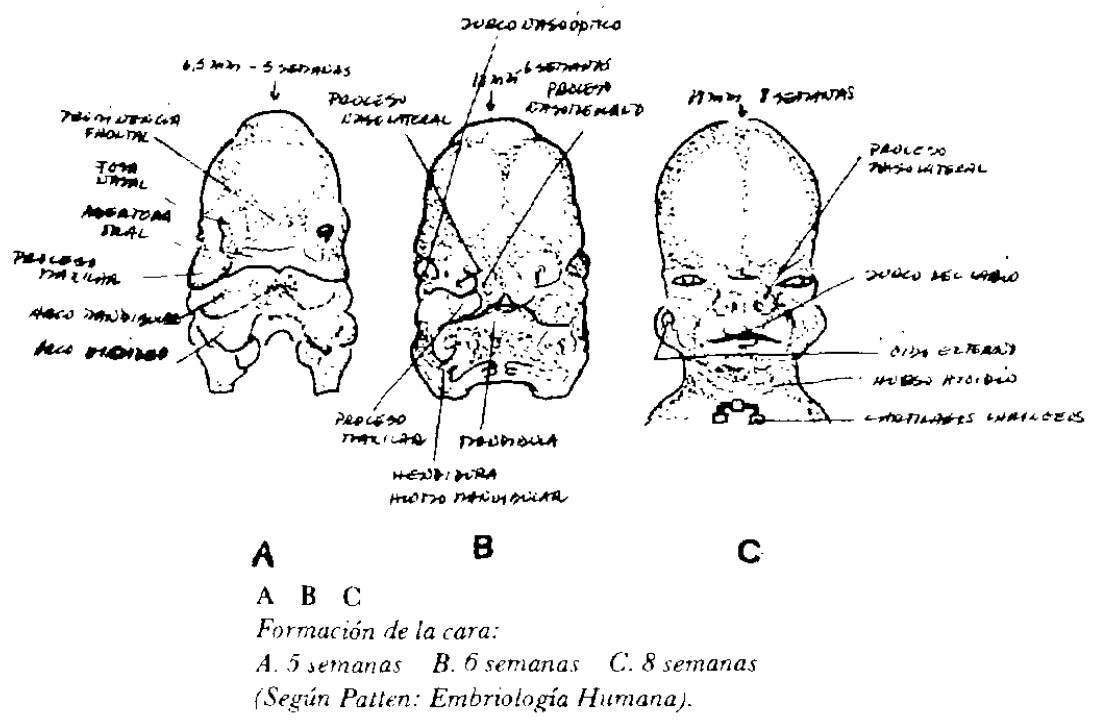

* Departamento de Genética, Hospital San Juan de Dios. 
Estos procesos van creciendo hacia la porción ventral para terminar por fusionarse al centro formando los arcos mandibulares, la nariz y la boca, uniéndose a los procesos nasales medio, lateral y nasocóptico más los procesos maxilares conjunto que forma propiamente la cara (Fig. 1). En dirección caudal, el arco mandibular formará la mandíbula inferior y el arco hioideo, el cuello. Entre ellos quedan numerosos surcos: el mandíbulo hioideo, partiendo de caudal a cefálica en el cual se desarrolla el oido medio, en su interior, y el externo en la parte externa y más posterior. El surco maxilo-mandibular, en el cual se desarrolla la abertura oral, futura boca (Fig. 1), el surco nasoóptico que separa la nariz de la órbita, el surco del labio superior que separa ambos procesos nasomedianos $y$ que al unirse formará el surco medio del labio superior, etc.

\section{IRRIGACIÓN DE LA CARA}

Todos los procesos y arcos que se han mencionado en la formación de la cara, están irrigados por las arterias carótidas. Estas arterias derivan de los primitivos arcos aórticos que son seis, y que unen las aortas dorsales con las ventrales. En realidad nunca están todos los arcos aórticos funcionando juntos en el embrión, ya que los dos primeros degeneran antes que se terminen de formar los últimos. Estos arcos aórticos se introducen en los tejidos de los arcos branquiales proporcionándoles su irrigación (Fig. 2). De las aortas dorsal y ventral se forman las carótidas. En la parte más cefálica la aorta dorsal forma la carótida primitiva, luego por sobre el tercer arco se continúa como carótida externa. La aorta ventral se une al tercer arco para formar la carótida interna (Fig. 2).

Más hacia caudal el cuarto arco forma a derecha el tronco braquiocefálico y a la izquierda el cayado de la aorta. El quinto arco se reabsorbe y del sexto se originan arterias vertebrales y el ductus. Como puede apreciarse, cualquier anomalía en esta importante irrigación embrionaria dará origen, a su vez, a importantes anomalías en la conformación de la enorme porción cefálica del embrión que a las 4 semanas, es igual a un tercio del total del volumen del embrión y que a las 6 semanas, ya es igual a la mitad de éste. Tal es la magnitud del crecimiento del polo encefálico entre la 3 y 7 semana de gestación, momento en que se producen estos cambios.
Fie. 2

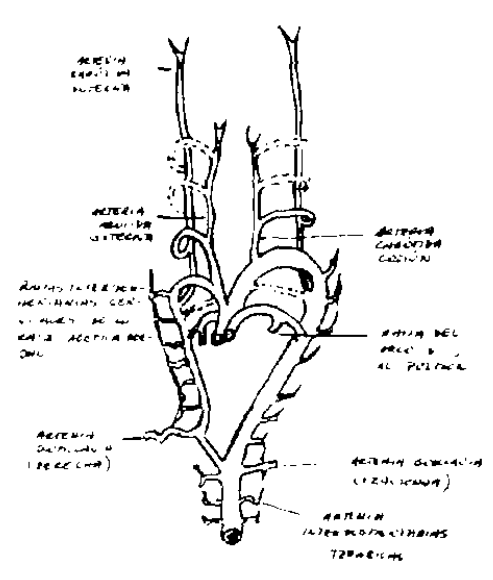

Segrin Patien

Continuando con nuestro estudio veremos cómo se forma el oído externo. En la porción más dorsal del surco mandíbulo-hioideo (Fig. 3), aparecen rodeándole 6 mameloncitos que forman como un semicírculo. Estos mamelones van creciendo y formando lo que será el pabellón y el conducto auditivo externo (Fig. 4).

Fig. 3
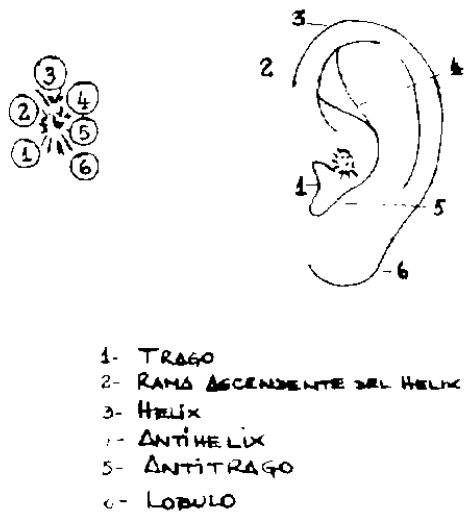

Procesos embronarios. Posución del oido.

Fig. 4

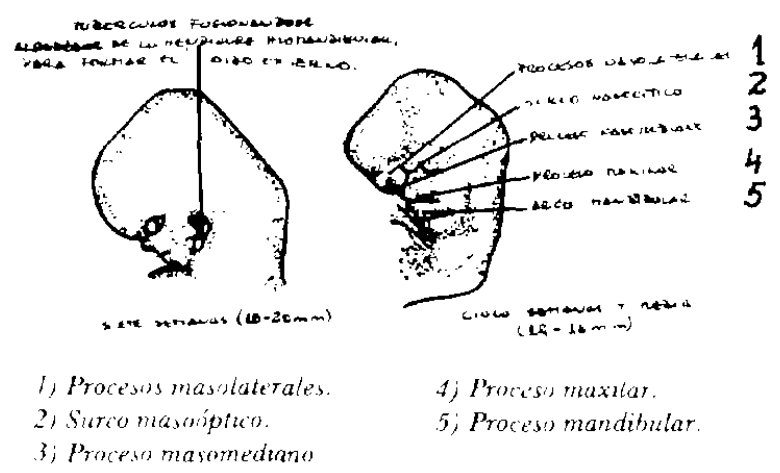


El oído medio se forma a partir de los surcos primero y segundo que, al unirse en el fondo, forma el primer esbozo de la cavidad timpánica y trompa de Eustaquio. En medio del mesénquima se empiezan a condensar los futuros huesecillos que, por un lado, contactarán con la ventana oval y por el otro con el tímpano. Tanto el oído externo como el medio comienzan a formarse alrededor de la $6^{2}$ semana de gestación, y 2 semanas después se encuentran casi terminados, pero el mesénquima que rodea los huesecillos comienza a reabsorberse rápidamente sólo en la última parte de la vida intrauterina, tanto que al nacer el niño aún hay tejido conjuntivo que termina por reabsorberse sólo en los primeros meses de vida, por lo cual la audición del niño recién nacido es muy deficiente. Al producirse la reabsorción del tejido de la caja del tímpano, ésta empieza a crecer y el tímpano que estaba cubierto por dentro por este tejido y por fuera por el tapón mucoso del conducto, es liberado. Este hecho, más el crecimiento de la caja, le da al tímpano la tensión que necesita para su función.

Luego de esta breve revisión a la embriogénesis de la cara, oído externo y medio, y la irrigación de estos elementos, teniendo una visión más dinámica de las alteraciones lógicas que pueden ocurrir, nos referiremos a los cuadros que con mayor frecuencia puede el médico encontrar en su práctica diaria.

Muchos son los cuadros clínicos que han sido incluidos en este síndrome. Mackenzie y Craig, en su síntesis incluyen algunos tan discutibles como la sordomudez por agenesia del yunque y el estribo, el hipertelorismo, y el síndrome de Waardenburg. Pero ninguno habla como perteneciente a esta entidad al labio leporino, que por lo menos en parte debería considerarse así.

\section{EI. Labio Leporino}

Es un cuadro que todo el mundo conoce; sin embargo, tiene muchos puntos obscuros en su etiopatogenia. Se sabe que puede ser producido por diversos factores: hormonales, vitamínicos, tóxicos, irradiaciones o genéticos (Fig. 5). De estos últimos, un buen porcentaje puede incluirse dentro del síndrome del primer arco.
Sabemos que su nombre no es muy apropiado, porque deriva del labio partido al medio de las liebres, cosa que sólo ocurre por excepción en el labio leporino, ya que su fisuración es siempre lateral. Su causa es la falla en la unión del proceso nasomediano con el proceso maxilar (Fig. 1B), y es por lo tanto lateral. No ocurre lo mismo con la fisura palatina, porque en ella la falla de fusión se produce a nivel de los procesos nasomedianos y maxilar entre sí, constituyendo el labio leporino propiamente tal, ya que la separación es central. A veces la falla de unión toma, también, el surco nasoóptico prolongándose hasta el ojo, comprometiendo el surco lacrimal. Ocasionalmente la deformación no compromete sólo la boca, sino toda la cara. En este caso las orejas no ascienden a su posición definitiva, quedando bajas, en alguna parte del camino que recorre el embrión. Suele ocurrir que la nariz no se desarrolle, o lo haga en forma deficiente. Ambos síndromes, la micrognatia y la agenesia nasal, han sido reconocidos como pertenecientes al grupo del primer arco. Sabemos, por último, que hay alteraciones cromosómicas que frecuentemente se acompañan de labio leporino (Figs. 5 y 6). Es muy posible que los genes alterados que producen esta malformación estén dentro de estos mismos cromosomas y que sean los causantes de esta enfermedad sin necesidad de existir una cromosomopatía.

Fig. 5

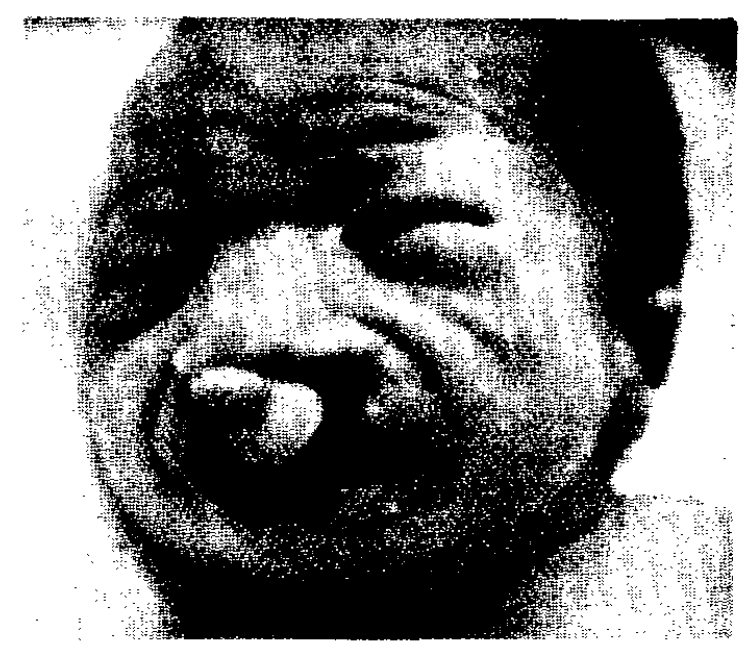

Labio leporno en trisemta $D$ 
Fig. 6

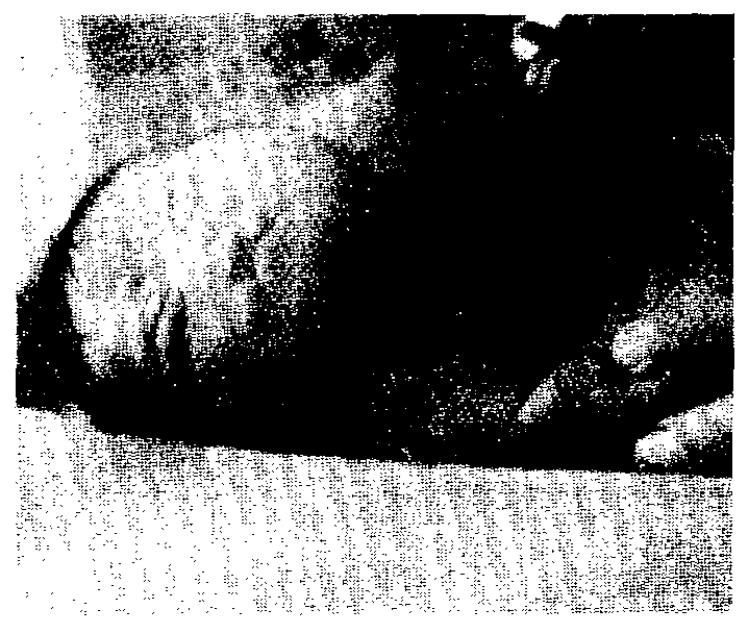

Labo leporino ientral en deleción del brazo corto del cromosoma

\section{El HIPERTELORISMO}

Fue Mackenzie el primero en incluir esta alteración dentro del síndrome del $1^{\text {er }}$ arco branquial. Su estudio es bastante completo e incluso su tipificación es difícil, ya que se ha confundido con la distocia intercantal. Se dice que un paciente tiene un hipertelorismo cuando presenta alteraciones en la conformación del cráneo, cuya manifestación más evidente es la separación exagerada de las cavidades orbitarias. Los valores promedios son de $30 \mathrm{~mm}$ para el diámetro intercantal y $60 \mathrm{~mm}$ para el interpupilar. G. Poch, en 1970, los clasificó en dos grupos: primario y secundario o asociado. Este último es el que encontramos como acompañante en diversos cuadros genéticos (Fig. 4). La forma primaria la divide Poch en:

Ocular pura. En esta forma sólo existe el Fig 7

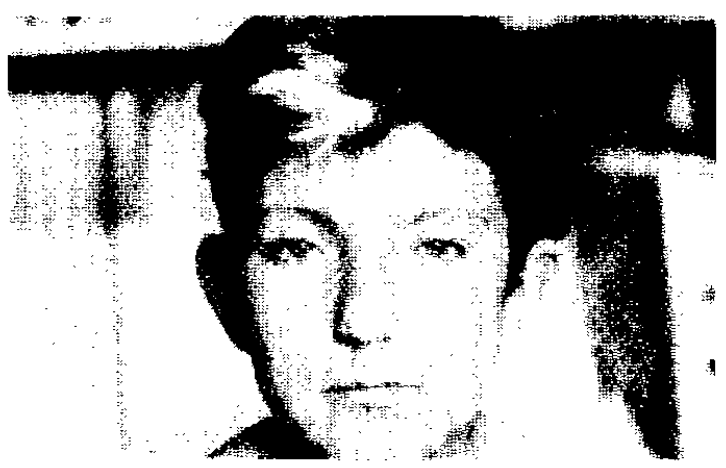

Mipertelorismo a sociado en sindrome de Waarderburg. hipertelorismo. No hay otros signos patológi$\cos$, la vida es normal y es la forma más frecuente de la afección.

Común. En esta forma se asocia el hipertelorismo con epilepsia. No hay alteraciones mentales.

Clásico o de Greig. Existe aquí una profunda oligofrenia, importantes alteraciones craneanas, pero no hay epilepsia.

Completa. En esta forma se asocian todos los signos patológicos descritos en las formas anteriores.

Genéticamente es un trastorno autosómico que puede presentarse como dominante o recesivo y seguramente de carácter poligénico de penetrancia variable.

\section{El síndrome de Pierre Robin}

En este cuadro predominan los defectos de la boca.

Se encuentran hipoplasia mandibular, glosoptosis $y$ hendidura palatina con posición posterior de la lengua, por lo que presentan frecuentemente crisis de asfixia en los primeros días de vida y requieren por esto de cuidados permanentes. El pronóstico, sin embargo, es bueno, ya que con el desarrollo tiende a corregir espontáneamente este defecto. Su herencia en autosómica dominante, de penetrancia variable. En los últimos años se han descrito algunas anomalías en los cromosomas del grupo A, sin que éstas puedan ser interpretadas como propias del síndrome.

\section{Síndrome de Treacher Collins}

Este cuadro es tal vez el más clásico del grupo.

Sin embargo, ha costado mucho diferenciarlo de otros cuadros similares como el de Franceschetti o el de Goldenhar. Se trata de una disostosis mandíbulo-facial, y en ella destacan los signos siguientes: fisuras palpebrales antimongoloides, malformación del pabellón auricular con atresia del conducto auditivo externo. Deformidad de los huesecillos del oído medio y sordera de conducción. Coloboma del párpado inferior entre el tercio medio y el interno. Hipoplasia de los huesos malar y cigomático más una marcada hipoplasia de la mandíbulamicrognatia con aspecto de cara de pájaro. Paladar ojival, fístulas ciegas entre el oído y la boca, defectos de implantación del cabello 
(patillas) (Fig. 8). Los signos pueden ser uni o bilaterales, esto último es lo más frecuente. Se puede encontrar, también, macrostomía, atresia nasal, dientes separados y ausencia del ángulo nasofrontal. Esta anomalía es la que hemos visto con mayor frecuencia en nuestro Departamento, contando con unos 15 casos en la casuística de estas alteraciones, lo que constituye un porcentaje del $75 \%$ del total Su herencia es autosómica dominante, de gran penetrancia. El mayor problema que presentan estos niños es su sordera de conducción. Sin embargo, suelen traer problemas, también, al ortodoncista por sus alteraciones faciales y dentales.

Fig. 8 A y B
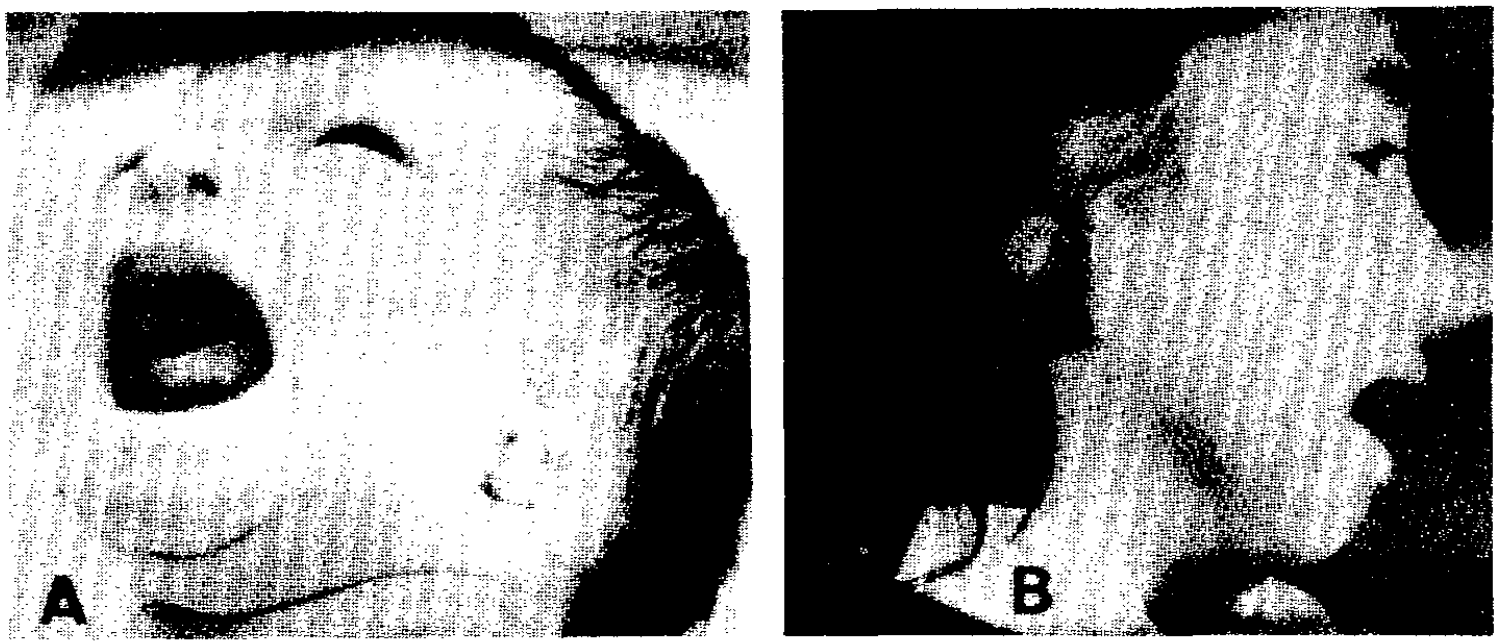

Síndrome de Treacher Colltns. Anormalidad pabellón $y$ conducto auditivo externo

\section{Sindrome de Franceschetti}

Cuadro muy similar al anterior y del cual aún se discute si realmente corresponde a un síndrome separado o es sólo una manifestación algo diferente del síndrome de $\mathrm{T}$. Collins. Los signos más relevantes de carácter propio serían: indemnidad de los pabellones auriculares que sólo se ven algo deformados; fístulas importantes y penetrantes aurículo-orales. El resto de los signos es común para ambos cuadros, destacando la atresia del conducto auditivo externo con sordera de conducción.

\section{Sindrome de Goldenhar}

Es este cuadro uno de los primeros descritos ya que Von Arlt lo hizo en el año 1845. Aun después de la descripción de Goldenhar en 1952 se discute si no es una forma del síndrome de T. Collins. Sin embargo, a pesar de tener muchos signos en común, creemos que tiene algunos propios que son suficientemente específicos como para su total diferenciación. Estos signos son: lipodermoides perilimbares; occipitalización del atlas y anomalías vertebrales en cuña; signo de Duane. El resto de los signos no son propios y pueden presentarse en ambos síndromes. Estos son: coloboma del párpado superior, aberturas palpebrales antimongólicas, pabellón auricular malformado, apéndices preauriculares en la línea de fusión nasomaxilar, hipoplasia de los arcos cigomáticos y del malar, sordera de conducción por atresia del conducto o malformación del oído medio, etcétera.

En nuestro Departamento de Genética hemos visto dos niños con este síndrome, uno de los cuales se publicó en otra revista en forma separada. Curiosamente, este paciente no tiene una sordera de conducción, como es lo clásico, sino una sordera leve de tipo neural (Fig. 9). 
Fig 9

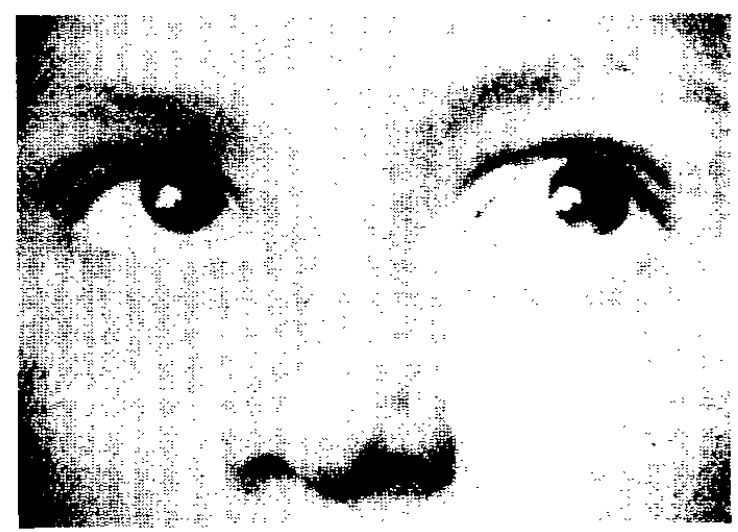

Sintrome de Goldenhar. Lipodermoudes perilumbar y colobansa párpado superior izquierdo.

No quisiera terminar esta breve exposición sobre el síndrome de primer arco branquial, sin referirme a algunas anomalías que por lo discretas no se les da la importancia debida y que pertenecen a este grupo. Merecen desta- car: la ausencia del lóbulo auricular, las malformaciones del mismo; las fístulas o papilomas preauriculares y la fistula aural, que se ubica siempre en la rama ascendente del hélix. Todas estas pequeñas anomalias del conducto auditivo con mayor o menor compromiso auditivo.

\section{REFERENCIAS}

Emerit, Ingrid. La Presse Medicale, Vol. 74, N 10, pág. 507, febrero 1966

Fazen, Louis. Am. J. Dis. Child, Vol. 113, April 1967.

Hetrera, J., M. Morales. El sindrome de Goldenhas. Rev. Chile. Ped. 48-178-182, 1977.

Herrera, J. Aspectos genéticos de algunas alteraciones otorrinológicas. Conferencia dada en el Congreso de Otorrinolaringología. Dic. 70.

Patten, Bradley M. Embriología Humana. Ed. El Ateneo, Buenos Aires.

Poch, Gustavo F. Hipertelorismo. Ed. Universitaria, Buenos Aires

Singh, Roderick P. Am. J. Dis. Child., Vol. 120, Dic. 1970.

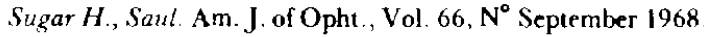

Trabajo entregado para su publicación en 1975. 